\title{
Static Compression Properties of Textile Pressure Sensor
}

\author{
Murakami Tetsuhiko ${ }^{\mathrm{a},}{ }^{*}$, Masuda Atsuji $^{\mathrm{a}}$, Iemoto Yoshiyuki ${ }^{\mathrm{b}}$, Uematsu Hideyuki ${ }^{\mathrm{b}}$, Tanoue Shuichi ${ }^{\mathrm{b}}$

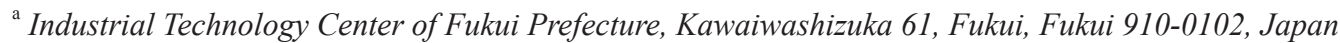 \\ ${ }^{\mathrm{b}}$ Graduate School of Engineering, University of Fukui, Bunkyo, Fukui, Fukui 910-8507, Japan
}

Received 22 May 2015; accepted for publication 28 September 2015

\begin{abstract}
There are no sensors, which satisfy all conditions such as flexibility, stretch, thinness and low cost although there are various sheet type pressure sensors. We have developed a new type of pressure sensor using the compression property of textile. We have already evaluated the response characteristics of the textile sensor.

This report shows the result of experiment about the static compression durability and recoverability of the textile sensor. About the static compression durability, the compression pressure decreased with an increase of the compression time of compression pressure. And the decreasing ratio of detectable pressure became small at large detectable pressure. The static compression recovery was performed when the compression time was short. However, this property was not recovered when the compression time was large.
\end{abstract}

Key Words: Textile sensor, Compression sensor, Electrically conductive yarn, Static compression durability, Static compression recoverability

\section{テキスタイルセンサーの静的圧縮特性}

村上哲彦 ${ }^{\mathrm{a}, *}$, 増田敦士 ${ }^{\mathrm{a}}$, 家元良幸 ${ }^{\mathrm{b}}$, 植松英之 ${ }^{\mathrm{b}}$, 田上秀一 ${ }^{\mathrm{b}}$

a 福井県工業技術センター, ${ }^{b}$ 福井大学大学院 工学研究科

\section{1. 緒 言}

大面積の圧力を検知するシートセンサーは, 柔軟性, 伸縮 性, 厚み, 価格などの観点から様々な材料や方法により開発 されている. 例えば, 薄くてフレキシブルな特性を有するシー トセンサーとしては, 導電性ポリマー [1], 織物 [2-3], 編 物 [4] 等の特性を活かしたシートセンサーが研究されている が, 導電性ポリマーによるフイルムセンサーは柔軟性, 伸縮 性, 耐久性に劣り, 静電容量法による織編物センサーは電気 回路の構成が繁雑で使用環境の影響を受けやすい等, 各々技 術課題があり，これらの問題点を解決したシートセンサーは 未だ実用化されていない.

福井県工業技術センターでは, 平二重袋織物の圧縮特性を 利用して圧力を検知できるテキスタイルセンサーを開発して いる [5-9]. このテキスタイルセンサーの断面写真を Fig. 1 に，テキスタイルセンサーの圧縮挙動モデルを Fig. 2 に示す.
テキスタイルセンサーの構造は, Fig. 1 および 2(a)に示すよ うに, 平二重袋織物の上層部と下層部に導電糸を交錯, かつ 接触しないように配置している。テキスタイルセンサーが圧 力を検知する原理を Fig. 2(b)に示す. すなわち, このテキス

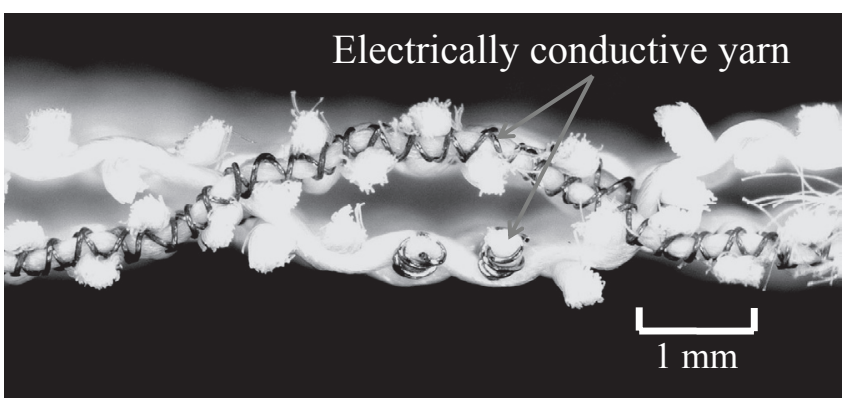

Fig. 1 Cross-sectional photograph perpendicular to weft yarn of the textile sensor.

* 連絡先：福井県工業技術センター 910-0102 福井市川合熟塚町 61

E-mail : murakamitetsuhiko@fklab.fukui.fukui.jp, Tel : +81-776-55-0664, Fax : +81-776-55-0665 
Electrically conductive yarn

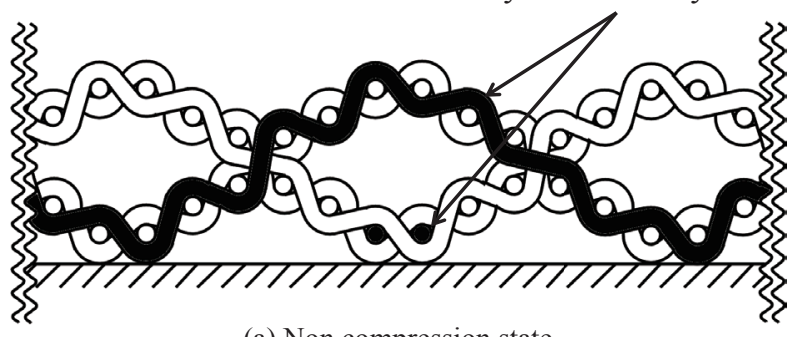

(a) Non compression state

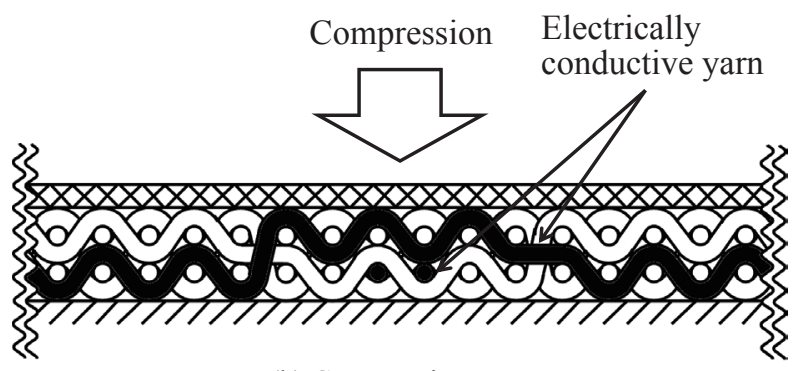

(b) Compression state

Fig. 2 Cross-sectional image perpendicular to weft yarn of the textile sensor.

タイルセンサーを圧縮したときに平二重袋織物の空間がつぶ れ，上下に配置した導電糸が接触する。この時に，導電糸を 含む電気回路には, 通電により電気信号の変化が生じるので, これをモニターすることで圧力を検知することができる。し たがって，従来のシートセンサーに比べて薄層で柔軟性に優 れおり, 導電糸の配置を変えることで, 任意の箇所に圧力検 知点を配置することができる。また，通常の織機で製造でき るため価格を抑えることができ, 織物製造工程を利用してい るため布帛を製造するように大面積化も容易である。さらに， テキスタイルセンサーは導電糸接触時の通電を利用した簡易 なシステムでの構成が可能であり, 複雑な電気回路を構築す る必要がなく，取り扱いが容易である等の利点が多い.

我々はこれまでテキスタイルセンサーの圧力検知応答性に

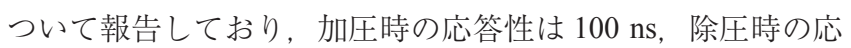
答性は $400 \mathrm{~ns}$ と応答性に優れていることを確認した。また， このテキスタイルセンサーの繰り返し検知が可能である周波 数領域は $30 \mathrm{~Hz}$ であり, 感圧スイッチとして適用が可能であ ることを明らかにした [10]. しかし，平二重袋織物の圧縮 特性を利用したテキスタイルセンサーであるため, センサー としての耐久性を明らかにする必要がある。そこで, 本報で はテキスタイルセンサーに静的圧縮圧力を付加したときの圧 縮特性である, 静的圧縮耐久性と静的圧縮回復性について検 討した。

\section{2. 実験方法}

\section{1 試料}

本研究で使用するテキスタイルセンサーの織物規格を
Table 1 に示す，導電糸には芯糸にポリエステル糸, カバード 糸に銅線を使用したダブルカバード糸を用いた。また，テキ スタイルセンサーの構造を維持する地糸には芯糸と同じポリ エステル糸をたて糸およびよこ糸に使用して,レピア織機 (津 田駒工業製FR001）にて製作した。また，テキスタイルセン サーのたて糸の導電糸は約 $25 \mathrm{~mm}$ 間隔で 2 本ずつ配置した. よこ糸の導電糸は 8 個の平二重袋織物の中央に, Fig. 2(a)に 示したように 2 本配置した。

\section{2 テキスタイルセンサーの静的圧縮試験評価}

テキスタイルセンサーの静的圧縮試験は, Fig. 3 に示すと おりテキスタイルセンサーの上下にポリ塩化ビニル製の板 (1 $\mathrm{mm}$ 厚）を設置し, 直径 $200 \mathrm{~mm}$ の金属製の重りにより圧縮 圧力 $10 \mathrm{kPa}$ (荷重 $320 \mathrm{~N}$ ), $20 \mathrm{kPa}$ (荷重 $620 \mathrm{~N}$ ), $40 \mathrm{kPa}$ (荷 重 $1,240 \mathrm{~N}$ ) の 3 種類の圧縮圧力を付加し, 圧縮圧力を付加 している時間 (圧縮圧力付加時間) は 24 時間から 480 時間 $(20$ 日間）により行った。静的圧縮試験前と静的圧縮試験中のテ キスタイルセンサーの検知した圧力（検知圧力）を測定する ことにより，静的圧縮耐久性を評価した。

テキスタイルセンサーの静的圧縮回復試験は, このセン サーに $20 \mathrm{kPa}$ の圧縮圧力で, 圧縮圧力付加時間を 72 時間 (3 日)と 480 時間 (20日) の 2 種類の付加時間で行った。 こ

Table 1 Textile standard of a textile sensor.

\begin{tabular}{|c|c|}
\hline $\begin{array}{l}\text { Ground } \\
\text { yarn }\end{array}$ & $\begin{array}{l}\text { Warp, Weft : } \\
\text { Polyester multifilament } 280 \mathrm{dtex} / 48 \mathrm{f} \\
\text { Twist yarn : } 600 \text { twist } / \mathrm{m} \\
\quad \text { (Toray Industries, Inc. Type 202) }\end{array}$ \\
\hline $\begin{array}{l}\text { Electrically } \\
\text { conductive } \\
\text { yarn }\end{array}$ & $\begin{array}{l}\text { Double covered yarn : } 3500 \text { twist } / \mathrm{m} \\
\text { Core : Polyester multifilament } 280 \mathrm{dtex} / 48 \mathrm{f} \\
\text { Twist yarn : } 600 \text { twist } / \mathrm{m} \\
\text { (Toray Industries, Inc. Type 202) } \\
\text { Skin : Copper wire of diameter } 0.05 \mathrm{~mm} \\
\text { (Sanshu Electric Wire Co., Ltd. Type A) }\end{array}$ \\
\hline Density & $\begin{array}{l}\text { Warp density : } 120 \text { ends/inch } \\
\text { Weft density : } 90 \text { picks/inch } \\
\text { In setting of weaving }\end{array}$ \\
\hline $\begin{array}{l}\text { Textile } \\
\text { structure }\end{array}$ & $\begin{array}{l}\text { Plane weave with double structure } \\
\text { Length of hollow : } 3.4 \mathrm{~mm}\end{array}$ \\
\hline
\end{tabular}

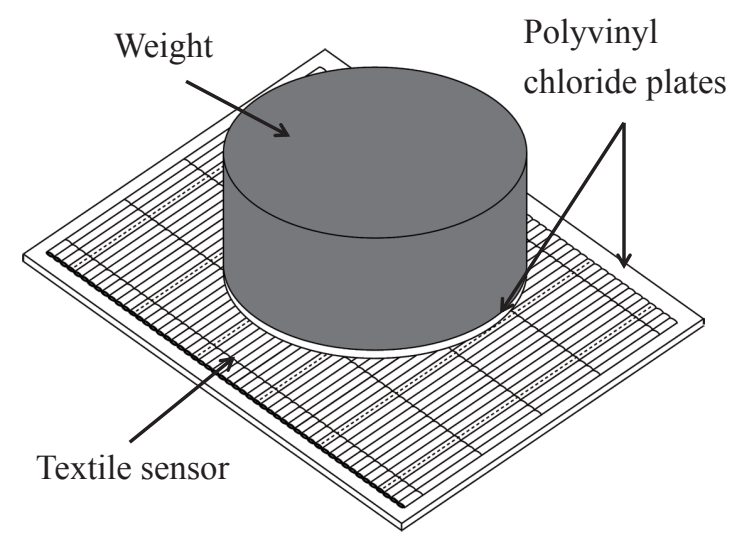

Fig. 3 Static compression examination image of the textile sensor. 
の静的圧縮後に除重し, 圧力を付加しない状態で静置した時 間（圧縮圧力回復時間）を 24 時間から 720 時間（30日間） に拈けるテキスタイルセンサーの検知圧力を測定することに より，静的圧縮回復性を評価した

テキスタイルセンサーの性能の評価に用いる検知圧力を測 定するために，テキスタイルセンサーを Fig. 4 に示すとおり スイッチとした電気回路を構成し，テキスタイルセンサーに 圧縮試験機（カトーテック製 KES-G5）で直径 $16 \mathrm{~mm}$ の加圧 子を用いて圧縮速度 $1 \mathrm{~mm} / \mathrm{s}$ で圧力を付加した。圧縮試験機 で圧縮するときのテキスタイルセンサーにかかる圧力, 固定 抵抗の電位差の時間に対する測定例を Fig. 5 に示す。テキス タイルセンサーの上層部と下層部の導電糸が接触しないとき は, 固定抵抗の電位差は約 $\pm 0.01 \mathrm{~V}$ で変動しており, 導電糸 の接触により図に示すとおり, 約 $4 \mathrm{~V}$ 以上の電位差が急激に 発生するので, 固定抵抗の電位差が $0.1 \mathrm{~V}$ になった時の圧力 をテキスタイルセンサーの検知圧力とした。なお， 1 つのテ キスタイルセンサーの導電糸の交錯部 25 箇所を 3 回ずつ計 75 回測定し, その平均值より検知圧力を求めた。

織物は弾性限界以上の力を加えたとき，ひずみが残留して 永久変形する $[11]$ 。そこで，テキスタイルセンサーの構造変

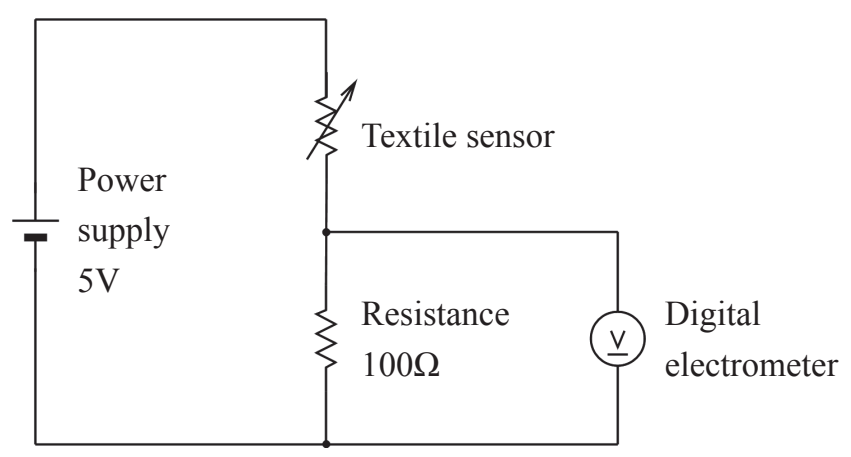

Fig. 4 Electric circuit containing the textile sensor.

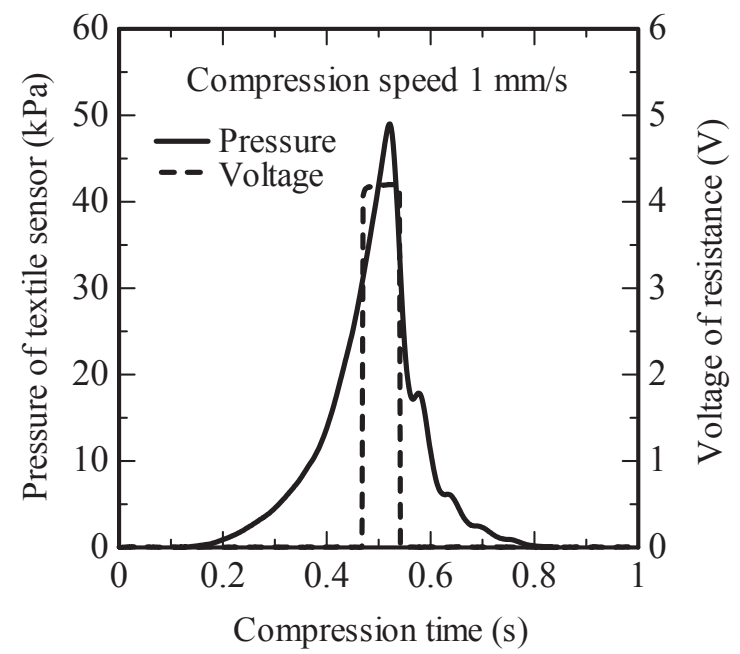

Fig. 5 Pressure of textile sensor and voltage of resistance vs static compression time.
形を評価するために，センサーの上層部と下層部の導電糸の 距離（導電糸間距離）を測定した。テキスタイルセンサーの 導電糸間距離は，センサーを圧縮した時に $49 \mathrm{~Pa}$ の圧力が検 知されてから固定抵抗の電位差が $0.1 \mathrm{~V}$ になるまでの圧縮距 離を測定し, それぞれの圧縮圧力付加時間後のテキスタイル センサー内 10 力所の平均值より導電系間距離を求めた。

\section{3. 実験結果および考察}

\section{1 テキスタイルセンサーの静的圧縮耐久性}

テキスタイルセンサーの静的圧縮耐久性の評価には, 静的 圧縮圧力をかけた後のテキスタイルセンサーの検知圧力を、 静的圧縮をかける前のテキスタイルセンサーの検知圧力の平 均 $29.2 \mathrm{kPa}$ で除した值で定義する検知圧力比を導入した。 キスタイルセンサーに $10 \mathrm{kPa}, 20 \mathrm{kPa}, 40 \mathrm{kPa}$ の静的圧縮圧 力を圧縮圧力付加時間 24 時間から 480 時間（20日間）まで 付加したときの検知圧力比を Fig. 6 に示す。図より，検知圧 力比は圧縮圧力を付加すると 1 以下になっている。これは, 検知圧力は静的圧縮をかける前の検知圧力より静的圧縮をか けた後の検知圧力が低くなるためであり，静的圧縮をかけた ことで，小さい圧縮圧力でセンサーが応答するようになった ことを意味している. その検知圧力比は圧縮圧力付加時間と ともに減少し, 圧縮圧力が増加することにより, 短い圧縮圧 力付加時間で検知圧力比が減少することが確認できた。また, 圧縮圧力 $10 \mathrm{kPa}, 20 \mathrm{kPa}$ を付加したときは, 圧縮圧力付加時 間を増加することにより, 圧縮圧力 $40 \mathrm{kPa}$ の検知圧力比に 近づく傾向がみられた。

織物の圧縮特性は 3 段階から構成されており,第 1 段階（圧 力 $<100 \mathrm{~Pa} ）$ は表面毛羽や突出繊維の曲げ変形の領域，第 2 段階（100 Pa <圧力 $<5 \mathrm{kPa} ）$ は繊維と繊維間の摩擦を伴う すべりによる変形の領域, 第 3 段階（5 kPa <圧力）は緘維 自体の横圧縮変形の領域と報告されている [12-13]。この報 告では, ポリエステル糸 $334 \mathrm{dtex}$ の加撚糸を使用した斜文織

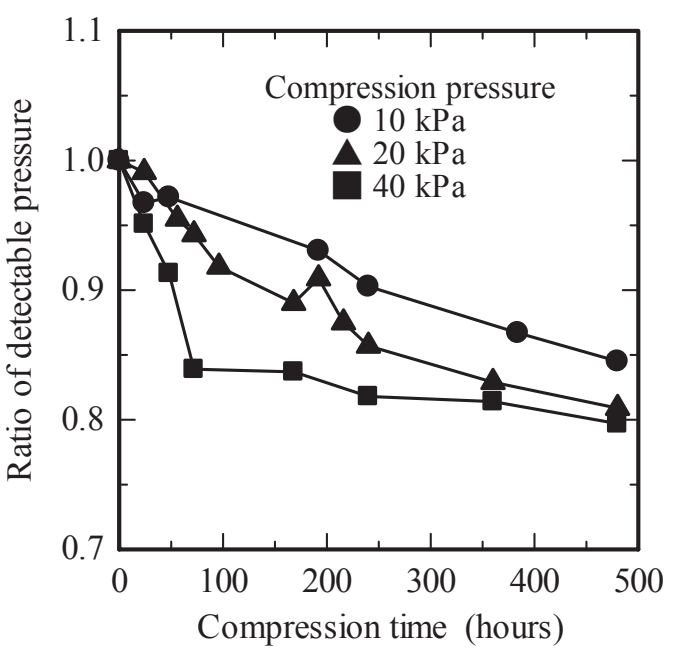

Fig. 6 Ratio of detectable pressure vs static compression time. 
物で試験を実施しており，本研究で用いたテキスタイルセン サー地糸のポリエステル糸 280 dtex の加撚糸と繊度が近く, テキスタイルセンサーの圧縮変形の参考とした。本研究では 圧縮圧力 $10 \mathrm{kPa}, 20 \mathrm{kPa}, 40 \mathrm{kPa}$ を付加しており, テキス夕 イルセンサーはフィラメント糸で構成されているので, 主に 第 2, 3 段階の圧縮変形が発生していると考えられる。この ような静的圧縮をかけることでセンサー内の糸と織物構造が 変形を起こし, 織物の二重構造がつぶれてしまうので, 圧力 検知させる前のセンサー内における上層部と下層部の導電糸 の距離が短くなると考えられ，このことが，静的圧縮をかけ たときの検知圧力の低下につながったと考えられる，そこで， それぞれの圧縮圧力付加時間をかけた後のテキスタイルセン サーの導電糸間距離を測定した。テキスタイルセンサーに圧 縮圧力 $20 \mathrm{kPa}$ を付加したときの導電糸間距離を Fig. 7 に示す. 図に示すとおり, 導電糸間距離は圧縮圧力付加時間とともに 減少し, 480 時間（20日）で約 $0.3 \mathrm{~mm}$ 以下に減少する傾向 がみられた。この傾向は, Fig. 6 に示す検知圧力比が圧縮圧 力付加時間の増大に伴い減少する傾向と類似している。よっ て，上述のように圧縮圧力と圧縮圧力付加時間によりテキス タイルセンサーを構成している糸と織物構造が変形し, その 空間が狭くなったことが原因で検知圧力が低下したことがわ かる。

\section{2 テキスタイルセンサーの静的圧縮回復性}

次に, 静的圧縮により変形したテキスタイルセンサーの 織物構造の回復性について評価した。Fig. 8 は, テキスタイ ルセンサーに $20 \mathrm{kPa}$ の静的圧縮圧力を 72 時間（3 日間）と 480 時間 (20日間) 付加後に除重した場合の, 圧縮圧力回復 時間と検知圧力比の関係を示した図である. 図に示すとおり， 検知圧力比は, 圧縮圧力回復時間とともに増加することが確 認できた. 圧縮圧力 $20 \mathrm{kPa} て ゙ 72$ 時間（3 日間）を付加した ときは, 検知圧力比が 720 時間 (30 日)後に 1 付近の值になり,

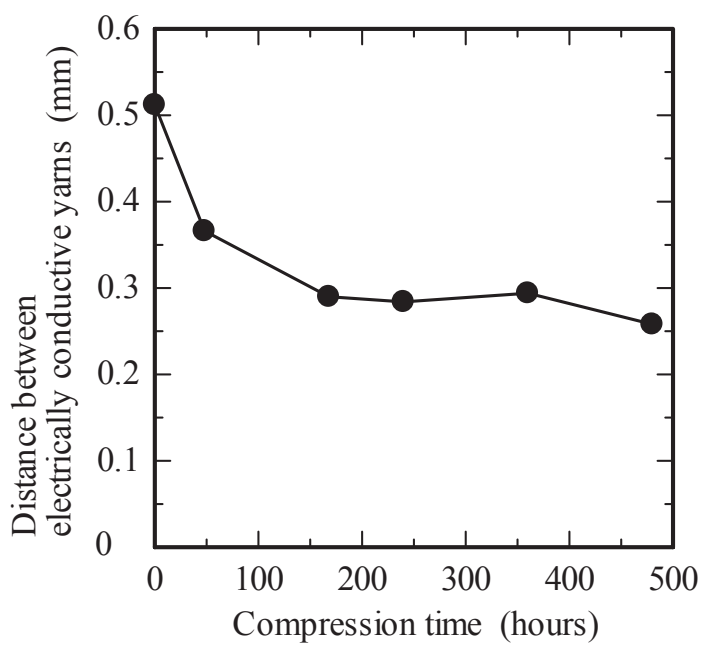

Fig. 7 Distance between electrically conductive yarns vs static compression time at static compression pressure of $20 \mathrm{kPa}$.

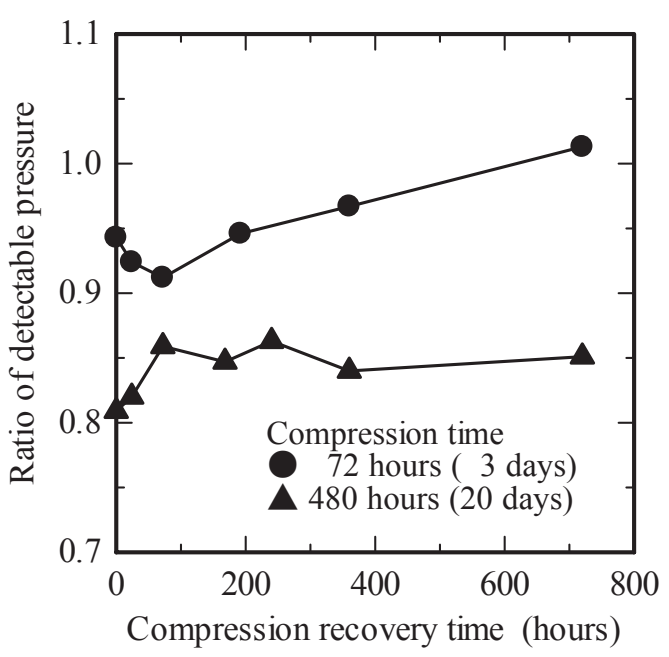

Fig. 8 Ratio of detectable pressure vs static compression recovery time at static compression pressure of $20 \mathrm{kPa}$.

完全に回復することがわかった。この結果から, 短時間の静 的荷重を付加した場合であれば，テキスタイルセンサー内の 第 2 段階の圧縮特性である繊維間のすべりを伴う変形と，第 3 段階の圧縮特性である繊維自体の横圧縮変形が回復し, テ キスタイルセンサーの糸と織物構造が静的荷重付加前と同等 に復元していると推察される。 また, 圧縮圧力 $20 \mathrm{kPa}$ で 480 時間（20日間）を付加したときは, 検知圧力比は長い圧縮圧 力回復時間であっても約 $85 \%$ にとどまり，長期間静的荷重 を付加した場合は圧縮特性が回復しないことがわかった。こ れは, 長時間の静的荷重の付加した場合は第 2，3段階の圧 縮変形により，テキスタイルセンサーの糸と織物構造が永久 変形し, 荷重付加前のセンサーの糸と織物構造に回復できな いほどに変形したことによると推測される。

\section{4. 結 言}

本報では, テキスタイルセンサーに静的圧縮圧力を付加し たときの圧縮特性について検討した。 得られた結果を以下に まとめる.

テキスタイルセンサーの静的圧縮耐久性については，(1) 圧縮圧力付加時間の増加とともに検知圧力が減少すること,

(2) 圧縮圧力が高いほど圧縮圧力付加時間の増加に対する検 知圧力の減少割合も大きくなること，がわかった。

テキスタイルセンサーの静的圧縮回復性については, 圧縮 圧力付加時間が短時間であれば, 検知圧力は圧縮圧力回復時 間とともに増加し, 圧縮圧力付加前の検知圧力に回復するが, 長時間の圧縮圧力を付加後の検知圧力は, 圧縮圧力付加前の 検知圧力に回復しないこと，がわかった。

今後は, テキスタイルセンサーの繰り返し圧縮耐久性や織 物規格と検知圧力の関係について検討する予定である。 


\section{謝 辞}

本研究を実施するに当たり, 実験でご協力頂いた福井大学 工学部卒業生 嵯峨祐輔氏に深く感謝申し上げます。

\section{References}

[1] Nitta Co Ltd (2006) Japanese Patent 3882172

[2] Fujioka J, Kuroda N (2014) J Text Mach Soc Japan, 67, 115-119

[3] Nagoya University (2014) Japanese Patent 5467322

[4] Suminoe Textile Co Ltd (2014) Japanese Patent 5457063

[5] Masuda A, Murakami T, Kondo K (2008) J Text Mach Soc Japan, 61, 809-814
[6] Fukui Prefecture (2009) Japanese Patent 4273233

[7] Fukui Prefecture (2010) Japanese Patent 4565109

[8] Fukui Prefecture, Utic Co Ltd (2013) Japanese Patent 5233055

[9] Fukui Prefecture (2013) Japanese Patent 5352795

[10] Masuda A, Murakami T, Kondo K, Sasaji T, Iemoto Y, Tanoue S (2010) J Text Eng, 56, 181-185

[11] Nakajima T, Kaneko E, Shimizu H, Gocho H, Muta M (2010) "Shinkou Hihukuzairyougaku", p177, Koseikan Co Ltd

[12] Matsudaira M, Qin H (1993) J Text Mach Soc Japan (predecessor journal of J Text Eng), 46, T226-T231

[13] Matsudaira M, Qin H (1995) J Text Mach Soc Japan (predecessor journal of J Text Eng), 48, T191-T195 
